\title{
Growth and role of the corpus luteum throughout delayed gestation in the potoroo, Potorous tridactylus
}

\author{
S. L. Bryant and R. W. Rose \\ Department of Zoology, University of Tasmania, Box 252C, G.P.O. Hobart, Tasmania 7001, \\ Australia
}

\begin{abstract}
Summary. The growth cycle of the corpus luteum (CL) of the potoroo is similar to that of other macropodids. During delayed gestation, the post-partum CL remains quiescent until it is reactivated by removal of the sucking pouch young. The CL then undergoes a period of growth, rapid from Day 6 until Day 12, followed by a gradual decline from Day 21 to Day 27.

Excision of the CL before Day 6 of pregnancy either inhibited embryonic development or failed to support it. Excision of the CL between 6 and 21 days after removal of pouch young did not prevent embryos developing to full term but interfered with parturition. Excision on Day 25 after removal of pouch young allowed birth but impaired lactation, neonates dying within 2 days. By Day 27, the CL appeared to be no longer essential for embryonic development, birth or neonate survival. It is suggested that the $\mathrm{CL}$ of the potoroo is required for a slightly greater proportion of pregnancy than in most larger kangaroos because the birth canal must be prepared before each parturition.
\end{abstract}

\section{Introduction}

In most macropodid marsupials, development of the post-partum corpus luteum is arrested during embryonic diapause (Tyndale-Biscoe, Hearn \& Renfree, 1974). Development resumes when either the pouch young is removed, suckling wanes or the stimulus is induced artificially (Tyndale-Biscoe \& Hinds, 1984). In the quokka, Setonix brachyurus, growth of the CL recommences within the first 4 days after removal of pouch young and continues until a maximum diameter is attained around Day 19 of the 27-day pregnancy. Ovariectomy of quokkas before 7 days after removal of pouch young will prevent the blastocyst from developing to term. However, for parturition to be successful, the ovaries are essential until much later in pregnancy (Tyndale-Biscoe, 1963).

Similarly, in the tammar, Macropus eugenii, removal of the CL before Day 8 in pregnancy prevents embryos developing to full term. Removal before Day 17 allows gestation to continue but inhibits parturition and, before Day 21, interferes with pouch young survival (Young \& Renfree, 1979). In the tammar and quokka, blastocyst development, parturition and perhaps lactation appear to require independently a secretion from the CL.

The macropodid marsupial Potorous tridactylus is rare on mainland Australia and, although more common in Tasmania, is a wholly protected species. The potoroo is polyoestrous and breeds throughout the year. It has an oestrous cycle length of 42 days (Hughes, 1962); the undelayed gestation period occupies 38 days and the length of delayed gestation (i.e. after removal of pouch young) is 29 days (Shaw \& Rose, 1979).

Members of the subfamily Potoroinae may be distinguished from most other kangaroos and wallabies by the presence of an anterior vaginal expansion (Moors, 1975) and, unlike most macropodids, they give birth via a transient median vaginal canal which develops and remains patent only at parturition (Pearson, 1945; Rose, 1978). The majority of macropodids retain the median vaginal canal after the first pregnancy. 
This study examines the growth cycle and considers the possible roles of the corpus luteum throughout pregnancy in the potoroo.

\section{Materials and Methods}

Thirty-one potoroos, with young, were captured from the wild. Pouch young aged between 20 and 100 days were removed from females to stimulate blastocyst development and this was designated as Day 0.

One female had a bilateral ovariectomy on Day 0; for the remainder of animals either the CL of pregnancy was removed or a control laparotomy was performed. Operations were undertaken on Days $3,6,12,18,21,25$ or 27 after removal of pouch young.

Ketamine hydrochloride, $100 \mathrm{mg}(0.15 \mathrm{ml}$ Ketalar per $\mathrm{kg}$; Parke-Davis, N.S.W. $)$ was administered (i.p.) as a premedical sedative; surgery was performed with the animal anaesthetized by halothane (Fluothane B.P., ICI, Australia) and oxygen. The reproductive tract was exposed via a medial incision low inside the pouch. In early stages of pregnancy, the CL was identified on the ovary by its pink coloration and vascularization. When no single gland was distinct, 2 or more glands were removed.

The CL of pregnancy was later identified according to weight, diameter, luteal cell size, density of cell cytoplasm and amount of connective tissue present. During control laparotomies, ovaries were held with forceps for a comparable length of time. A pregnant uterus was recognizable by 14 days after removal of pouch young (Shaw \& Rose, 1979).

In the potoroo, birth is expected about 29 days after removal of pouch young (Shaw \& Rose, 1979), and females failing to give birth by 4 days after this time (i.e. Day 33) were re-examined or killed.

Excised CL were weighed and their maximum diameter measured using a microscope graticule. Glands were fixed in $10 \%$ buffered formalin and later embedded in paraffin wax. Sections were cut at $6 \mu \mathrm{m}$ and slides were routinely stained with Ehrlich's haematoxylin and eosin. Ovaries, uteri, vaginae and some mammary glands were also prepared for histological examination.

\section{Results}

Of the 31 animals examined, 10 were excluded from the results. When two or more CL were excised from the one ovary, not all the glands assumed the regressed appearance indicative of corpora albicantia. In some cases, histological examination of $\mathrm{CL}$ removed from the contralateral ovaries suggested that both were active. Of the 10 females, 7 had corpora lutea removed which did not correspond to the expected stage of development (Shaw \& Rose, 1979) and dimensions of these glands have not been included in Fig. 1. The remaining 3 females appeared to be non-pregnant at the time of operation but as their CL appeared similar to those of pregnant animals, the CL were removed and their dimensions were included in Fig. 1.

\section{Growth of the corpus luteum}

Between Days 0 and 3 after removal of pouch young the corpus luteum has a diameter in the range of 1.4 to $2.7 \mathrm{~mm}$ (Shaw \& Rose, 1979; this study). The quiescent gland had poorly defined luteal cell boundaries but the luteal cell nuclei were rounded, stained darkly and were finely granular but lacked prominent nucleoli. At Day 3 the gland had larger cell nuclei and an increase in cell cytoplasm.

A rapid period of growth, involving diameter (Fig. 1a), weight (Fig. 1b), size and nuclear diameter of luteal cells (Shaw \& Rose, 1979) occurred from Day 6 to Day 12; thereafter some decline in size occurred between Days 21 and 27. 


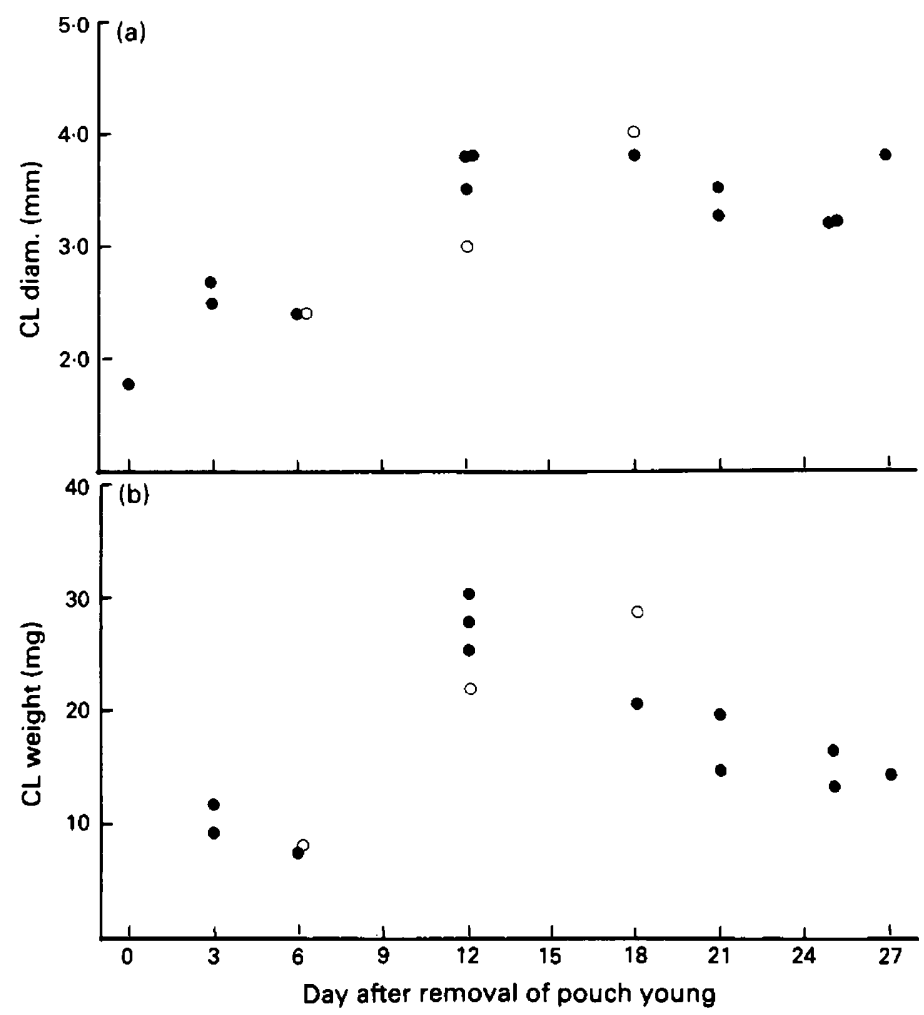

Fig. 1. Scattergram of the diameter (a) and weight (b) of corpora lutea removed throughout delayed gestation in the potoroo. Birth is expected near Day 29 ( $O$, not pregnant; 0 , pregnant).

No weight was obtained for the CL at Day 0 but weight increased from about $10 \mathrm{mg}$ at Day 3 to reach a maximum of $25-30 \mathrm{mg}$ at Day 12 . The $C L$ declined in weight after Day 12 and weighed $14-16 \mathrm{mg}$ before parturition.

From Day 21 onwards, cellular degeneration was evident in the CL. Luteal cell membranes were irregular, cytoplasmic vacuoles became numerous and increasing amounts of connective tissue were present in the gland. Although the CL still had a relatively large diameter $(3.8 \mathrm{~mm})$ at Day 27 , its weight was less than that of corpora lutea at Day 12 and, histologically, it appeared degenerate with large cytoplasmic vacuoles and dense connective tissue.

\section{Removal of the corpus luteum}

Days 0 and 3. The 3 experimental animals (1 ovariectomized, 2 with CL excised) failed to give birth by Day 33 and, no embryonic material was recovered from the uteri or reproductive tracts. An absence of cornified epithelia in the lateral vaginae suggested that females were not approaching oestrus. The Day 0 control animal gave birth at Day 32 and successfully raised the young. No newborn was observed for the Day 3 control animal.

Days 6-21. Corpora lutea were excised on Day $6(\mathrm{~N}=1)$, on Day $12(\mathrm{~N}=3)$, on Day 18 $(\mathrm{N}=1)$ and on Day $21(\mathrm{~N}=2)$. No births were observed for any of these 7 females. However, examination at Day 33 showed that 5 of the females had a retained fetus within the uterus. None of the fetuses had traversed the uterus into the median vagina. Of the 5 fetuses, 2 had weights similar to those of newborns (310 mg, Day 12; $297 \mathrm{mg}$, Day 21) and one, although partly resorbed, had a 
head measurement ( $4.7 \mathrm{~mm}$, Day 12) also similar to that of a newborn. The remaining 2 fetuses had weights (612 mg, Day 6; $562 \mathrm{mg}$, Day 21) and body measurements equivalent to 3-day-old pouch young. Fetuses were normal in development but grey discoloration indicated that all had died before re-examination of the mother.

Although there were several open spaces in the median vaginal canals of the 5 females with unborn fetuses, no canal was open for the full length. A rugose epithelium extended high into the lumina of the median vaginae and various cellular aggregations and tissue strands were dispersed throughout the folds.

Mammary glands from the animals with CL excised on Days 6 or 12 had undergone some proliferation by Day 33, according to the criteria used by Findlay (1982), but they did not display the large rounded alveoli with lipid fractions, characteristic of a lactating gland.

The 2 remaining experimental animals (Day 12, Day 18) both died within 3 days of operation. At autopsy they were still pregnant and measurements suggested that the embryos had continued to develop after removal of the CL.

Two of the 4 control animals gave birth (Day 29, Day 30 ) and successfully raised the young. A third control animal had a large vacant uterus, suggesting that birth had occurred.

Day 25. The 2 animals with excised CL successfully gave birth on Day 30 and Day 31 . The neonates were observed attached to their mother's teat after birth but within 2 nights both pouch young had died. Their emaciated appearance suggested that little growth had occurred since birth and their weights after 2 days $(288 \mathrm{mg}, 295 \mathrm{mg}$ ) were equivalent (or less) to those of a newborn pouch young. It was not possible, either by manual stimulation or with injections of oxytocin ( 2 i.u.; Syntocinon, Sandoz, N.S.W.), to induce a milk flow from the mother, before or after the neonates had died.

The 2 control animals both gave birth on Day 29 and suckled their young in a normal manner.

Because both experimental animals gave birth, they were not killed and so no examination of the reproductive tract or mammary glands was undertaken.

Day 27. In the single female from which CL were excised at this time, a pouch young was observed attached to a teat in the mother's pouch on Day 28. Growth and development of the young proceeded as normal.

\section{Discussion}

Measurements of corpus luteum weight, diameter and histology throughout gestation indicate that the CL of potoroos has a life cycle similar to that of other wallabies (Renfree, Green \& Young, 1979). During quiescence and early pregnancy, the luteal cells and luteal nuclei are relatively small with little cytoplasm. The gland has a period of rapid growth 6 days after removal of pouch young, peaking in size around Day 12. It undergoes some decline in diameter and weight between Days 21 and 27.

Both Flynn (1922) and Hughes (1962) have commented on the presence of numerous CL in potoroos and, although the histological appearance of the $\mathrm{CL}$ is not a good guide to its importance in the maintenance of pregnancy (Tyndale-Biscoe \& Hawkins, 1977), the finding of several apparently active glands in the one animal warrants further investigation.

It appears that the $\mathrm{CL}$ of the potoroo has roles throughout pregnancy that are very similar to those of other kangaroos and wallabies (Tyndale-Biscoe, 1963; Renfree \& Tyndale-Biscoe, 1973; Tyndale-Biscoe \& Hawkins, 1977; Young \& Renfree, 1979). Removal of the CL between Days 0 and 6 after removal of pouch young probably inhibited or failed to support blastocyst development. As a luteal endometrium is not formed until 6 days after removal of pouch young (Shaw \& Rose, 1979), any brief resumption of development in the blastocyst after excision of CL on Day 3 may have resulted in its loss by Day 33. As no blastocysts were recovered at Day 33, it is possible that some animals were not pregnant. 
No information was obtained regarding premature ovulation after early excision of CL.

Excision of CL between Days 6 and 21 after removal of pouch young did not prevent embryos developing to term, but did interfere with parturition. Ovariectomy or $\mathrm{CL}$ excision midway through gestation in the quokka (Tyndale-Biscoe, 1963) and tammar (Young \& Renfree, 1979) also inhibits birth but not prior embryonic development.

All fetuses recovered from the potoroo failed to traverse the vaginal complex and remained within the uterus. Either the uterine contractions were insufficient to move the fetus into the vaginal complex or the cervix, or the anterior vaginal expansion and median vagina were inadequately prepared to allow fetal passage. The latter may well be due to a lack of relaxin and/or progesterone, produced in the marsupial $C L$ and thought to be involved in the preparation of the median vaginal canal for parturition (Tyndale-Biscoe, 1963, 1969, 1981). Ward \& Renfree (1984) also found that tammar fetuses were retained in the uterus or aborted after administration of relatively high concentrations of progesterone late in pregnancy. Some other ratio of hormones may be required to stimulate parturition (Lemon, 1972; Renfree et al., 1979; Hinds \& Tyndale-Biscoe, 1982; Tyndale-Biscoe, Hinds, Horn \& Jenkin, 1983).

After an early luteal secretion in the potoroo, which results in uterine stimulation and blastocyst activation, the $C L$ is no longer responsible for the maintenance of gestation. The primary function of the $\mathrm{CL}$ between Days 6 and 21 after removal of pouch young is to initiate mammary gland development and to prepare the female tract for parturition, a process which is completed around Day 25 .

Removal of CL on Day 25 in the potoroo may interfere with lactation, perhaps by affecting the final maturation of the mammary gland and/or milk secretion. Inability of the pouch young to suck may also be a consideration. Findlay (1982) reported that the mammary gland of the tammar has a period of growth during early pregnancy but shows only little development until around the time of birth. Findlay, Ward \& Renfree (1983) suggest that lactogenesis may be triggered when a threshold of prolactational hormones is reached, regardless of progesterone concentration.

The critical period during which excision of CL results in term, but unborn, fetuses is Days 6 to 17 in the tammar (Young \& Renfree, 1979), after Day 7 in the quokka (Tyndale-Biscoe, 1963) and Days 6 to 21 in the potoroo (present study). The tammar is dependent on the CL for at least 23 days of the 27-day pregnancy if pouch young are to survive. The ovaries of the quokka have been removed at Day 19 without affecting pouch young survival. In the potoroo, this dependence on the CL extends almost the entire length of delayed gestation, until about Day 27 of the 29-day period.

The potoroo may be dependent upon the CL for a slightly longer period than are other macropodids, because the median vaginal canal has to be prepared before each parturition. In most other macropodids, once this canal is developed it remains patent throughout their subsequent reproductive life. In the larger macropodines, it may be that the CL of the first pregnancy (i.e. before the development of the median vagina) is required for a longer period than in subsequent pregnancies but experimental data on this point have yet to be obtained.

We thank Dr C. H. Tyndale-Biscoe for his criticisms of an earlier manuscript and the Tasmanian National Parks and Wildlife Service for the permit to obtain the potoroos.

\section{References}

Findlay, L. (1982) The mammary glands of the tammar wallaby (Macropus eugenii) during pregnancy and lactation. J. Reprod. Fert. 65, 59-66.

Findlay, L., Ward, K.L. \& Renfree, M.B. (1983) Mammary gland lactose, plasma progesterone and lactogenesis in the marsupial Macropus eugenii. J. Endocr. 97, 425-436.

Flynn, T. (1922) Notes on certain reproductive phenomena in some Tasmanian marsupials. Ann. Mag. nat. Hist. Ser. 9X, 225-231.

Hinds, L.A. \& Tyndale-Biscoe, C.H. (1982) Plasma progesterone levels in the pregnant and non-pregnant tammar, Macropus eugenii. J. Endocr. 93, 99-107.

Hughes, R.L. (1962) Reproduction in the macropod marsupial Potorous tridactylus (Kerr). Aust. J. Zool. 10, 193-223. 
Lemon, M. (1972) Peripheral plasma progesterone during pregnancy and the oestrous cycle in the tammar wallaby, Macropus eugenii. J. Endocr. 55, 63-71.

Moors, P.J. (1975) The urogenital system and notes on the reproductive biology of the female rufous rat-kangaroo, Aepyprymmus rufescens (Gray) (Macropodidae). Aust. J. Zool. 23, 355-36I.

Pearson, J. (1945) The female urogenital system of the Marsupialia, with special reference to the vaginal complex. Pap. \& Proc. Roy. Soc. Tasmania 71-99.

Renfree, M.B. \& Tyndale-Biscoe, C.H. (1973) Intrauterine development after diapause in the marsupial Macropus eugenii. Devl Biol. 32, 28-40.

Renfree, M.B., Green, S.W. \& Young, I.R. (1979) Growth of the corpus luteum and its progesterone content during pregnancy in the tammar wallaby, Macropus eugenii. J. Reprod. Fert. 57, 131-136.

Rose, R.W. (1978) Reproduction and evolution in female Macropodidae. Aust. Mamm. 2, 65-72.

Shaw, G. \& Rose, R.W. (1979) Delayed gestation in the potoroo Potorous tridactylus (Kerr). Aust. J. Zool. 27, 901-912.

Tyndale-Biscoe, C.H. (1963) Effects of ovariectomy in the marsupial Setonix brachyurus. J. Reprod. Fert. 6, $25-40$.

Tyndale-Biscoe, C.H. (1969) Relaxin activity during the oestrous cycle of the marsupial, Trichosurus vulpecula (Kerr). J. Reprod. Fert. 19, 191-193.
Tyndale-Biscoe, C.H. (1981) Evidence for relaxin in marsupials. In Relaxin, pp. 225-232. Eds G. BryantGreenwood, H. Nial \& F. Greenwood. Elsevier/North Holland, Amsterdam.

Tyndale-Biscoe, C.H. \& Hawkins, J. (1977) The corpora lutea of marsupials: Aspects of function and control. In Reproduction and Evolution, pp. 245-251. Eds J. Calaby \& C. H. Tyndale-Biscoe. Australian Academy of Science, Canberra.

Tyndale-Biscoe, C.H. \& Hinds, L.A. (1984) Seasonal patterns of circulating progesterone and prolactin and response to bromocriptine in the female tammar Macropus eugenii. Gen. comp. Endocr. 53, 58-68.

Tyndale-Biscoe, C.H., Hearn, J.P. \& Renfree, M.B. (1974) Control of reproduction in macropodid marsupiais. J. Endocr. 63, 589-614.

Tyndale-Biscoe, C.H., Hinds, L.A., Horn, C.A. \& Jenkin, G. (1983) Hormonal changes at oestrus, parturition and post-partum oestrus in the tammar wallaby (Macropus eugenii). J. Endocr. 96, 155-161.

Ward, K.L. \& Renfree, M.B. (1984) Effects of progesterone on parturition in the tammar, Macropus eugenii. J. Reprod. Fert. 72, 21-28.

Young, I.R. \& Renfree, M.B. (1979) The effects of corpus luteum removal during gestation on parturition in the tammar wallaby (Macropus eugenii). J. Reprod. Fert. 56, 249-254.

Received 7 June 1985 